\title{
BAURAN PROMOSI MEMPENGARUHI PENGAMBILAN KEPUTUSAN MAHASISWA MEMILIH UNIVERSITAS MUHAMMADIYAH BENGKULU
}

\author{
Mukhlizar \\ Universitas Muhammadiyah Bengkulu, Indonesia \\ mukhlizarmukhtar23@gmail.com
}

\begin{abstract}
ABSTRAK
Penelitian ini bertujuan untuk mengetahui advertising $\left(\mathrm{X}_{1}\right)$, sales promotion $\left(\mathrm{X}_{2}\right)$ personal selling $\left(\mathrm{X}_{3}\right)$ publisitas $\left(\mathrm{X}_{4}\right)$ direct marketing $\left(\mathrm{X}_{5}\right)$ secara parsial dan secara simultan berpengaruh signifikan terhadap pengambilan keputusan mahasiswa memilih Universitas Muhammadiyah Bengkulu. Penelitian ini menggunakan pendekatan kuantitatif dengan metode eksplanatory research, sumber data primer melalui penyebaran kuesioner, data sekunder dari publikasi informasi dan sumber lainnya. Kuesioner disebarkan kepada 193 sampel penelitian berasal dari mahasiswa angkatan 2018-2019. Hasil penelitian bahwa dari lima variabel bauran promosi ada tiga variabel yang secara parsial berpengaruh signifikan terhadap pengambilan keputusan mahasiswa, yakni variabel advertising, public relation, dan direct marketing, sedangkan yang tidak berpengaruh signifikan yakni variabel sales promotion dan personal selling. Secara simultan bauran promosi meliputi advertising $\left(\mathrm{X}_{1}\right)$, sales promotion $\left(\mathrm{X}_{2}\right)$, personal selling $\left(\mathrm{X}_{3}\right)$, public relation $\left(\mathrm{X}_{4}\right)$ dan direct marketing $\left(\mathrm{X}_{5}\right)$ berpengaruh signifikan terhadap pengambilan keputusan mahasiswa.
\end{abstract}

Kata Kunci: Bauran Promosi, Keputusan Memilih.

\begin{abstract}
This study aims to determine advertising (X1), sales promotion (X2) personal selling (X3) publicity (X4) direct marketing (X5) partially and simultaneously have a significant effect on student decision making choosing Muhammadiyah University Bengkulu. This study uses a quantitative approach with explanatory research methods, primary data sources through questionnaires, secondary data from information publications and other sources. Questionnaires were distributed to 193 research samples from 2018-2019 students. The results showed that of the five promotion mix variables, there were three variables that partially had a significant effect on student decision making, namely advertising, public relations, and direct marketing variables, while those that had no significant effect were sales promotion and personal selling variables. Simultaneously the promotion mix includes advertising (X1), sales promotion (X2), personal selling (X3), public relations (X4) and direct marketing (X5) have a significant effect on student decision making.
\end{abstract}

Keywords: Promotional Mix, Choice Decision 


\section{PENDAHULUAN}

Ditengah persaingan yang begitu ketat, Universitas Muhammadiyah Bengkulu (UMB) yang sesuai visi "Menjadi perguruan tinggi terdepan dalam IPTEKS dan peradaban kampus yang Islami pada tahun 2028”, terus memperbaiki diri. Upaya ini dapat dilakukan dengan mengadopsi dan menerapkan inovasi sistem pendidikan yang mampu meningkatkan kualitas, citra dan daya saing.

Pengelolaan perguruan tinggi memerlukan keterpaduan antara kepentingan sosial dengan pendekatan promosi dan pemasaran. Adapun kualitas sebuah lembaga tidak akan diketahui masyarakat luas apabila tidak adanya kegiatan promosi, dan dari promosi akan menghasilkan suatu opini dalam pengambilan keputusan dari calon mahasiswa untuk memilih Universitas Muhammadiyah Bengkulu (UMB).

Jumlah mahasiswa merupakan unsur terpenting dalam kemajuan dan perkembangan yang signifikan terhadap Universitas Muhammadyah Bengkulu. Peningkatan jumlah mahasiswa bukan hanya dapat membantu perguruan tinggi untuk tetap mendapat keuntungan saja namun juga dapat memberikan kontribusi efektif akan kebutuhan pendidikan masyarakat, serta mampu meningkatkan kualitas civitas akademik secara keseluruhan.

Sebagai lembaga pendidikan Universitas Mummadiyah Bengkulu haruslah mampu meningkatkan mutu dan kualitas layanan kepada mahasiswa dalam upaya peningkatan jumlah calon mahasiswa yang berminat mendaftarkan diri di Universitas Mummadiyah Bengkulu. Untuk memperolah citra yang baik karena dinilai masyarakat sebagi universitas yang memiliki pilihan yang tepat untuk melanjutkan studi perguruan tinggi maka Universitas Mummadyah Bengkulu diharapkan mampu untuk menghadapi persaingan dalam menarik minat calon mahasiswa dengan melakukan kegiatan promosi sebagai tindakan komunikasi untuk menyebarluaskan keunggulan-keunggulan yang dimiliki Universitas Mummadiyah Bengkulu.

Kenaikan jumlah mahasiswa sangat dipengaruhi oleh keinginan calon mahasiwa untuk memutuskan melanjutkan studi di Universitas Mummadyah Bengkulu. Berdasarkan hal di atas, peneliti beranggapan bahwa penelitian tentang faktor-faktor yang mempengaruhi perilaku mahasiswa memilih melanjutkan kuliah di perguruan tinggi swasta sangat diperlukan terutama dalam strategi pemasaran untuk mempertahankan atau meningkatkan jumlah mahasiswa di masa yang akan datang. Keputusan tamatan SMA di kota Bengkulu dan sekitarnya dalam memilih sebuah perguruan tinggi dipengaruhi oleh berbagai faktor, salah satunya adalah bauran pemasaran. Bauran pemasaran adalah suatu alat pemasaran yang digunakan untuk menjalankan suatu pemasaran. Di mana inti dari kegiatan pemasaran yaitu produk, harga, tempat, orang, pelayanan dan proses. Bauran pemasaran jasa memiliki pengaruh pemasaran yang kuat terhadap keberhasilan suatu strategi bauran pemasaran. Dalam memahami pemasaran jasa untuk perguruan tinggi, strategi yang diterapkan tidak terlepas dari dari strategi bauran 
pemasaran itu sendiri. Strategi bauran pemasaran dalam hubungannya dengan pemasaran jasa perguruan tinggi tidak terlepas dari produk, harga, promosi, lokasi, orang, proses dan pelayanan.

Agar promosi yang dilakukan dapat memberikan hasil yang maksimal perlu adanya bauran promosi, yaitu kombinasi strategi yang paling baik dari variabel-variabel periklanan, personal selling, dan alat promosi yang lain, yang semuanya direncanakan untuk mencapai program penjualan. Dalam tiga tahun terakhir, Universitas Muhammadiyah Bengkulu mengalami masa pasang surut dalam penerimaan calon mahasiswa baru.

Sebelum memutuskan untuk memasukkan anak ke perguruan tinggi swasta tertentu, orangtua mendapat informasi dari bauran promosi. Lingkungan yang mempengaruhi keputusan orang tua antara lain lingkungan kultural, politik dan hukum, ekonomi dan teknologikal, kompetitif, dan sumber daya dan sarana prasarana. Inputnya adalah rangsangan atau motivasi yang mendorong calon yang dipengaruhi oleh faktorfaktor tersebut. Schiffman dan Kanuk menyatakan bahwa keputusan adalah seleksi terhadap dua pilihan alternatif atau lebih (Schiffman \& Kanuk, 2010). Dengan perkataan lain, pilihan alternatif harus tersedia bagi seseorang ketika mengambil keputusan.

Sejauh pengamatan penulis, secara akademik memang sudah banyak yang meneliti bauran promosi, seperti penelitian Lontoh tentang bauran pemasaran, hasil temuan penelitiannya adalah secara simultan bahwa penjualan pribadi, periklanan, promosi penjualan, hubungan masyarakat dan pemasaran langsung berpengaruh secara signifikan terhadap keputusan pembelian. Secara parsial penjualan pribadi, periklanan, promosi penjualan, hubungan masyarakat dan pemasaran langsung berpengaruh secara signifikan terhadap keputusan pembelian (Lontoh, 2016). Kemudian penelitian Indasari, penelitian tersebut menggunakan teori pilihan rasional dari Weber yang menyatakan bahwa tindakan rasional berhubungan dengan pertimbangan yang sadar dan pilihan bahwa tindakan itu dinyatakan (Indasari, 2016). Pengertian rasional disini adalah masuk akal (Johnson, 1994). Metode penelitian tersebut berupa penelitian kuantitatif, dengan hasil bahwa dari analisis path diketahui bahwa iklan tidak berpengaruh terhadap primary buying motive, hanya mempengaruhi selective selective buying motives dan patronage buying motives, akan tetapi patronage buying motives tidak berpengaruh terhadap preferensi mahasiswa.

Selajutnya studi dilakukan oleh Dewa Bagus Nugraha Windusara dan A.A. Gd Agung Artha Kusuma, menyatakan bahwa teknik analisis regresi linier berganda menunjukkan secara langsung, simultan dan parsial promotion mix berdampak pada keputusan pembelian oppo smartphone (Windusara \& Kusuma, 2015). Berdasarkan hasil penelusuran, penelitian mengenai bauran promosi ratarata penelitian terdahulu lebih banyak meneliti pengaruh bauran promosi atau komunikasi pemasaran pada lembaga bisnis atau perusahaan komersial. Sementara penelitian ini lebih melihat bauran promosi pada lembaga pendidikan 
dalam melihat keputusan memilih tempat kuliah oleh calon mahasiswa, penelitian ini berbeda dengan penelitian yang pernah ada. Beberapa penelitian yang telah dilakukan merupakan penelitian yang memiliki perbedaan dalam hal subjek, metode, tempat, serta waktu penelitian. Penelitian ini lebih mendalam dan menekankan pengaruh bauran promosi terdiri advertising $\left(\mathrm{X}_{1}\right)$, sales promotion $\left(\mathrm{X}_{2}\right)$ personal selling $\left(\mathrm{X}_{3}\right)$ Publisitas $\left(\mathrm{X}_{4}\right)$ direct marketing $\left(\mathrm{X}_{5}\right)$ terhadap Pengambilan Keputusan Mahasiswa Memilih Universitas Muhammadiyah Bengkulu (UMB).

\section{METODE PENELITIAN}

Penelitian ini menggunakan pendekatan kuantitatif dengan menggunakan metode eksplanatory research. Variabel penelitian terdiri atas variabel bebas dan terikat. Variabel bebas adalah: advertising $\left(X_{1}\right)$, sales promotion $\left(\mathrm{X}_{2}\right)$, personal selling $\left(\mathrm{X}_{3}\right)$, public relation $\left(\mathrm{X}_{4}\right)$ dan direct marketing $\left(\mathrm{X}_{5}\right)$ dan variabel terikat Keputusan Memilih (Y). Pengambilan sampel secara probabilita teknik systematical sampling, Berdasarkan jumlah mahasiswa baru angkatan 2018, total populasi 1821 orang, yang menjadi populasi sasaran sesuai teknik systematical sampling ada 6 program studi yang mahasiswa barunya di atas 100 orang yakni program studi Teknik Informatika, Ekonomi Manajemen, Akuntansi, Hukum, Pendidikan Bahasa Indonesia, sehingga populasi sasaran dalam penelitian ini berjumlah 968 orang, pengambilan sampel sebanyak 20\%. Sampel dalam penelitian ini memiliki 6 jenis kelompok dengan jumlah populasi 968 mahasiswa angkatan 2018-2019, sampel penelitian didapat sebayak 193 orang.

Tabel 1 Populasi dan Sampel Penelitian

\begin{tabular}{llccc}
\hline No & \multicolumn{1}{c}{ Program Studi } & Populasi & Populasi & Jumlah Sampel \\
\hline 1 & Teknik Informatika & 190 & $20 \%$ x 190 & 38 \\
2 & Ekonomi Manajemen & 340 & $20 \% \times 340$ & 68 \\
3 & Akuntansi & 176 & $20 \% \times 176$ & 35 \\
4 & Hukum & 160 & $20 \% \times 160$ & 32 \\
5 & Pendidikan Bahasa Indonesia & 102 & $20 \% \times 102$ & 20 \\
\hline \multicolumn{2}{c}{ TOTAL } & $\mathrm{N}=968$ & $\mathrm{n}=193$ \\
\hline
\end{tabular}

Data primer menggunakan metode kuesioner, sedangkan data sekunder dari buku-buku serta sumber bacaan lain yang relevan dan mendukung penelitian. Skala pengukuran digunakan untuk mengklarifikasi variabel yang akan diukur menggunakan skala likert. Skala likert digunakan untuk mengukur sikap, pendapat, dan persepsi seseorang atau sekelompok orang tentang fenomena sosial. Opini akan diukur melalui pernyataan-pernyataan yang terdapat pada kuisioner dan menggunakan skala likert dengan skala 1 sampai 5. Alternatif jawaban tersebut dikembangkan dengan menggunakan skala likert yang berupa jawaban sangat setuju (SS), setuju (S), kurang setuju (KS), tidak setuju (TS), dan sangat tidak setuju (STS). 
Tabel 2 Skala Pengukuran Kuesioner Berdarkan Intervalnya

\begin{tabular}{ccccc}
\hline No & Alternatif jawaban & Akronim & Skor Nilai (+) & Skor Nilai (-) \\
\hline 1 & Sangat Setuju & SS & 5 & 1 \\
2 & Setuju & S & 4 & 2 \\
3 & Kurang Setuju & KS & 3 & 3 \\
4 & Tidak Setuju & TS & 2 & 4 \\
5 & Sangat Tidak Setuju & STS & 1 & 5 \\
\hline
\end{tabular}

Teknik analisis data menggunakan analisis regresi linier berganda, untuk mengetahui arah hubungan antara variabel independen dengan variabel dependen apakah masing-masing variabel independen berhubungan positif atau negatif dan untuk memprediksi nilai dari variabel dependen apabila nilai variabel independen mengalami kenaikan atau penurunan. Persamaan regresi linear berganda sebagai berikut:

$$
\mathrm{Y}=\mathrm{a}+\mathrm{b} 1 \mathrm{X} 1+\mathrm{b} 2 \mathrm{X} 2+\mathrm{e}
$$

Uji t digunakan untuk mengetahui secara parsial pengaruh masing-masing variabel bebas terhadap variabel terikat, dengan asumsi bahwa: Jika $\mathrm{P}$ value $<\alpha$, maka Ho ditolak, Ha diterima. Uji F digunakan untuk menguji pengaruh variabel bebas secara bersama-sama terhadap variabel terikat, dengan asumsi bahwa: Jika $\mathrm{P}$ value $<\alpha$, maka Ho ditolak, Ha diterima, yang berarti: ada pengaruh signifikan bauran promosi meliputi advertising $\left(\mathrm{X}_{1}\right)$, sales promotion $\left(\mathrm{X}_{2}\right)$, personal selling $\left(\mathrm{X}_{3}\right)$, public relation $\left(\mathrm{X}_{4}\right)$ dan direct marketing $\left(\mathrm{X}_{5}\right)$ terhadap pengambilan keputusan mahasiswa memilih Universitas Muhammadiyah Bengkulu pada tingkat kepercayaan $95 \%$.

\section{HASIL PENELITIAN}

Analisis regresi linier berganda merupakan analisis pengaruh setiap variabel bebas secara bersama-sama terhadap variabel terikat. Analisis ini digunakan untuk mengetahui besarnya pengaruh dua atau lebih variabel bebas dengan cara bersama terhadap satu variabel terikat, maka akan diketahui pengaruh positif, pengaruh negatif, signifikan dan tidak signifikan. Sementara untuk menguji hipotesis secara parsial dilakukan dengan uji t dan untuk menguji hipotesis secara bersama-sama/simpultan dilakukan uji f.

\section{Hasil Analisis Regresi Linier Berganda}

Adapun analisis regresi pengaruh Advertising $\left(\mathrm{X}_{1}\right)$, Sales Promotion $\left(\mathrm{X}_{2}\right)$, Personal Selling $\left(\mathrm{X}_{3}\right)$, Publisitas/Public Relation $\left(\mathrm{X}_{4}\right)$, dan Direct Marketing $\left(\mathrm{X}_{5}\right)$ terhadap Keputusan Memilih Universitas Muhammadiyah Bengkulu berikut: 
Tabel 3 Hasil Uji Regresi Linier Berganda

\begin{tabular}{|c|c|c|c|c|c|c|}
\hline \multicolumn{7}{|c|}{ Coefficients ${ }^{\mathrm{a}}$} \\
\hline & & \multicolumn{2}{|c|}{$\begin{array}{l}\text { Unstandardized } \\
\text { Coefficients }\end{array}$} & \multirow{2}{*}{$\begin{array}{c}\text { Standardized } \\
\text { Coefficients } \\
\text { Beta }\end{array}$} & \multirow[b]{2}{*}{$\mathrm{t}$} & \multirow[b]{2}{*}{ Sig. } \\
\hline \multicolumn{2}{|c|}{ Model } & $\mathrm{B}$ & Std. Error & & & \\
\hline \multirow[t]{6}{*}{1} & (Constant) & .249 & .125 & & 1.989 & .048 \\
\hline & Advertising & .176 & .080 & .186 & 2.200 & .029 \\
\hline & sales promotion & .024 & .080 & .025 & .306 & .760 \\
\hline & personal selling & -.141 & .074 & -.146 & -1.918 & .057 \\
\hline & public relation & .581 & .084 & .572 & 6.893 & .000 \\
\hline & direct marketing & .293 & .070 & .302 & 4.186 & .000 \\
\hline
\end{tabular}

Adapun bentuk model persamaan regresi yang dapat dituliskan dari tabel di atas dalam persamaan regresi sebagai berikut:

$$
Y=0.249+0.176 X_{1}+0.024 X_{2}+(-0.141) X_{3}+0.581 X_{4}+0.293 X_{5}
$$

Persamaan regresi di atas kaitannya dengan variabel penelitian dapat dijelaskan sebagai berikut:

1. Konstanta memiliki nilai sebesar 0.249 yang berarti jika variabel-variabel Advertising $\left(\mathrm{X}_{1}\right)$, Sales Promotion $\left(\mathrm{X}_{2}\right)$, Personal Selling $\left(\mathrm{X}_{3}\right)$, Public Relation $\left(\mathrm{X}_{4}\right)$ dan Direct Marketing $\left(\mathrm{X}_{5}\right)$ bernilai 0, maka variabel Keputusan memilih Univeristas Muhammadiyah Bengkulu memiliki nilai sebesar 0.249.

2. Koefisien regresi variabel Advertising $\left(\mathrm{X}_{1}\right)$ mempunyai arah positif dalam pengaruhnya terhadap keputusan memilih Univeristas Muhammadiyah Bengkulu.

3. Koefisien regresi variabel Sales Promotion $\left(\mathrm{X}_{2}\right)$ mempunyai arah positif dalam pengaruhnya terhadap keputusan memilih Univeristas Muhammadiyah Bengkulu.

4. Koefisien regresi variabel Personal Selling $\left(\mathrm{X}_{3}\right)$ mempunyai arah negatif dalam pengaruhnya terhadap keputusan memilih Univeristas Muhammadiyah Bengkulu.

5. Koefisien regresi variabel Public Relation $\left(\mathrm{X}_{4}\right)$ mempunyai arah positif dalam pengaruhnya terhadap keputusan memilih Univeristas Muhammadiyah Bengkulu.

6. Koefisien regresi variabel Direct Marketing $\left(\mathrm{X}_{5}\right)$ mempunyai arah positif dalam pengaruhnya keputusan memilih Univeristas Muhammadiyah Bengkulu.

\section{Uji t}

Uji t digunakan untuk melihat pengaruh masing-masing variabel bebas

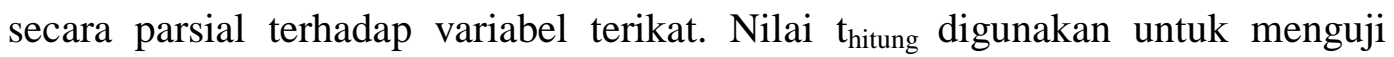
pengaruh secara parsial pada variabel Advertising $\left(\mathrm{X}_{1}\right)$, Sales Promotion $\left(\mathrm{X}_{2}\right)$, 
Personal Selling $\left(\mathrm{X}_{3}\right)$, Public Relation $\left(\mathrm{X}_{4}\right)$ dan Direct Marketing $\left(\mathrm{X}_{5}\right)$ terhadap variabel terikatnya.

Apakah variabel-variabel tersebut memiliki pengaruh yang signifikan terhadap keputusan memilih Univeristas Muhammadiyah Bengkulu (Y) atau tidak, dengan tingkat kesalahan $5 \%$. Uji ini dilakukan dengan melihat nilai signifikansi pada masing-masing variabel Independent (bebas) dengan taraf signifikansi $<0.05$. Untuk mengetahui pengaruh masing-masing variabel independent, maka digunakan uji $\mathrm{t}(\mathrm{t}-$ test) yaitu dengan cara membandingkan nilai $\mathrm{t}_{\text {hitun }}$ dengan $\mathrm{t}_{\text {tabel}}$, sedangkan nilai $\mathrm{t}$ tabel pada alpha sebesar $5 \%$ dapat diperoleh angka sebesar 1,973 pada taraf nyata $5 \%(\alpha=0,05)$ atau perbandingan nilai signfikan $\mathrm{t}$. Apabila $\mathrm{t}_{\text {hitung }}>\mathrm{t}_{\text {Tabel }}$ atau nilai Sig.t $<0,05$ berari $\mathrm{H}_{\mathrm{O}}$ ditolak, sebaliknya $t_{\text {hitung }}<t_{\text {tabel }}$ atau nilai Sig.t $>0,05$ berari $\mathrm{H}_{\mathrm{O}}$ diterima.

Tabel 4 Perbandingan Antara Nilai thitung dengan $t_{\text {tabel }}$

\begin{tabular}{|c|c|c|c|}
\hline Variabel & & Nilai & Status \\
\hline $\begin{array}{l}\text { Variabel Advertising berpengaruh secara signifikan } \\
\text { terhadap keputusan memilih }\end{array}$ & $\begin{array}{l}\mathrm{t}_{\text {hitung }} \\
\text { Sig. } \mathrm{t} \\
\mathrm{t}_{\text {tabel }}\end{array}$ & $\begin{array}{l}=2.200 \\
=0.029 \\
=1.973\end{array}$ & Signifikan \\
\hline $\begin{array}{l}\text { Variabel Sales Promotion tidak berpengaruh secara } \\
\text { signifikan terhadap keputusan memilih }\end{array}$ & $\begin{array}{l}\mathrm{t}_{\text {hitung }} \\
\text { Sig. } \mathrm{t} \\
\mathrm{t}_{\text {tabel }}\end{array}$ & $\begin{array}{l}=0.306 \\
=0.760 \\
=1.973\end{array}$ & $\begin{array}{l}\text { Tidak } \\
\text { Signifikan }\end{array}$ \\
\hline $\begin{array}{l}\text { Variabel Personal Selling berpengaruh secara } \\
\text { signifikan terhadap keputusan memilih }\end{array}$ & $\begin{array}{l}\mathrm{t}_{\text {hitung }} \\
\text { Sig. } \mathrm{t} \\
\mathrm{t}_{\text {tabel }}\end{array}$ & $\begin{array}{l}=-1.918 \\
=0.057 \\
=1.973\end{array}$ & $\begin{array}{l}\text { Tidak } \\
\text { Signifikan }\end{array}$ \\
\hline $\begin{array}{l}\text { Variabel Public Relation berpengaruh secara signifikan } \\
\text { terhadap keputusan memilih }\end{array}$ & $\begin{array}{l}\mathrm{t}_{\text {hitung }} \\
\text { Sig. } \mathrm{t} \\
\mathrm{t}_{\text {tabel }}\end{array}$ & $\begin{array}{l}=6.893 \\
=0.000 \\
=1.973\end{array}$ & Signifikan \\
\hline $\begin{array}{l}\text { Variabel Direct Marketing berpengaruh secara } \\
\text { signifikan terhadap keputusan memilih }\end{array}$ & $\begin{array}{l}\mathrm{t}_{\text {hitung }} \\
\text { Sig. } \mathrm{t} \\
\mathrm{t}_{\text {tabel }}\end{array}$ & $\begin{array}{l}=4.186 \\
=0.000 \\
=1.973\end{array}$ & Signifikan \\
\hline
\end{tabular}

Sumber: hasil penelitian, diolah tahun 2020

Berdasarkan tabel 4 merupakan perbandingan hasil perhitungan antara thitung dengan tabel, pada baris variabel merupakan bunyi hipotesis yang diajukan secara parsial dan pada baris status setelah melihat perbandingan antara thitung dengan tabel apakah seignifikan atau tidak signifikan, dengan melihat baris kolom t dan nilai sig. Pada hasil koefisiensi regresi linier berganda di atas selanjutnya akan dilakukan pengujian hipotesis yang dilakukan secara parsial sebagai berikut:

1. Variabel Advertising $\left(\mathrm{X}_{1}\right)$ berpengaruh positif dan signifikan terhadap keputusan memilih Univeristas Muhammadiyah Bengkulu. Hal ini dibuktikan dengan hasil pengujian yang menunjukkan nilai sig. advertising ( $\left.\mathrm{X}_{1}\right)$ 0.057> 0.050. dan nilai $\mathrm{t}_{\text {tabel }}=\mathrm{t}(\alpha, \mathrm{n}-\mathrm{k}-1)=(0.05,192-5-1)=(0.05 ; 186)=1.973$. Dengan demikian $\mathrm{t}_{\text {hitung }}$ lebih besar dari t tabel $(2.200>1.973) \mathrm{maka}_{\mathrm{o}}$ ditolak 
dan $\mathrm{H}_{\mathrm{a}}$ diterima, sehingga hipotesis yang berbunyi advertising $\left(\mathrm{X}_{1}\right)$ secara parsial berpengaruh signifikan terhadap pengambilan keputusan mahasiswa memilih Universitas Muhammadiyah Bengkulu, maka $\mathrm{H}_{\mathrm{a}}$ diterima.

2. Variabel Sales Promotion $\left(\mathrm{X}_{2}\right)$ tidak berpengaruh terhadap keputusan memilih Univeristas Muhammadiyah Bengkulu. Hal dibuktikan dengan hasil pengujian yang menunjukkan nilai sig. Sales Promotion $\left(\mathrm{X}_{2}\right) 0.760>0.050$. dan nilai $\mathrm{t}$ tabel $=\mathrm{t}(\alpha, \mathrm{n}-\mathrm{k}-1)=(0.05,192-5-1)=(0.05 ; 186)=1.973$. Dengan demikian $\mathrm{t}_{\text {hitung }}$ lebih kecil dari $\mathrm{t}$ tabel $(\mathbf{0 . 3 0 6}<1.973)$ maka $\mathrm{H}_{\mathrm{o}}$ diterima dan $\mathrm{H}_{\mathrm{a}}$ ditolak, sehingga hipotesis yang berbunyi sales promotion $\left(\mathrm{X}_{2}\right)$ secara parsial tidak berpengaruh signifikan terhadap pengambilan keputusan mahasiswa memilih Universitas Muhammadiyah Bengkulu, maka $\mathrm{H}_{\mathrm{a}}$ ditolak.

3. Variabel personal selling $\left(\mathrm{X}_{3}\right)$ berpengaruh negatif terhadap keputusan memilih Univeristas Muhammadiyah Bengkulu. Hal dibuktikan dengan hasil pengujian yang menunjukkan nilai sig. personal selling $\left(\mathrm{X}_{3}\right) 0.029<0.050$. dan nilai $\mathrm{t}_{\text {tabel }}=\mathrm{t}(\alpha, \mathrm{n}-\mathrm{k}-1)=(0.05,193-5-1)=(0.05 ; 187)=1.973$. Dengan demikian $\mathrm{t}_{\text {hitung }}$ lebih kecil dari $\mathrm{t}_{\text {tabel }}(-1.918<1.973)$ maka $\mathrm{H}_{\mathrm{o}}$ diterima dan $\mathrm{H}_{\mathrm{a}}$ ditolak, sehingga hipotesis yang berbunyi personal selling $\left(\mathrm{X}_{3}\right)$ secara parsial berpengaruh signifikan terhadap pengambilan keputusan mahasiswa memilih Universitas Muhammadiyah Bengkulu, maka $\mathrm{H}_{\mathrm{a}}$ ditolak.

4. Variabel Publisitas/Public Relation $\left(\mathrm{X}_{4}\right)$ berpengaruh positif dan signifikan terhadap keputusan memilih Univeristas Muhammadiyah Bengkulu. Hal dibuktikan dengan hasil pengujian yang menunjukkan nilai sig. Public Relation $\left(\mathrm{X}_{4}\right) 0.00<0.050$. dan nilai $\mathrm{t}_{\text {tabel }}=\mathrm{t}(\alpha, \mathrm{n}-\mathrm{k}-1)=(0.05,193-5-1)=$ $(0.05 ; 187)=1.973$. Dengan demikian $\mathrm{t}_{\text {hitung }}$ lebih besar dari $\mathrm{t}$ tabel $(6.893>$ 1.973) maka $\mathrm{H}_{\mathrm{o}}$ ditolak dan $\mathrm{H}_{\mathrm{a}}$ diterima, sehingga hipotesis yang berbunyi public relation $\left(\mathrm{X}_{4}\right)$ secara parsial berpengaruh signifikan terhadap pengambilan keputusan mahasiswa memilih Universitas Muhammadiyah Bengkulu, maka $\mathrm{H}_{\mathrm{a}}$ diterima.

5. Variabel Direct Marketing $\left(\mathrm{X}_{5}\right)$ berpengaruh positif dan signifikan terhadap keputusan memilih Univeristas Muhammadiyah Bengkulu. Hal dibuktikan dengan hasil pengujian yang menunjukkan nilai sig. Direct Marketing $\left(\mathrm{X}_{5}\right)$ $0.00<0.050$. dan nilai $\mathrm{t}$ tabel $\mathrm{t}(\alpha, \mathrm{n}-\mathrm{k}-1)=(0.05,193-5-1)=(0.05 ; 187)=$ 1.973. Dengan demikian $\mathrm{t}_{\text {hitung }}$ lebih besar dari $\mathrm{t}_{\text {tabel }}(4.186>1.973)$ maka $_{\mathrm{o}}$ ditolak dan $\mathrm{H}_{\mathrm{a}}$ diterima, sehingga hipotesis yang berbunyi direct marketing $\left(\mathrm{X}_{5}\right)$ secara parsial berpengaruh signifikan terhadap pengambilan keputusan mahasiswa memilih Universitas Muhammadiyah Bengkulu, maka $\mathrm{H}_{\mathrm{a}}$ diterima.

Berdasarkan hasil perhitungan SPSS, untuk memudahkan dalam membaca hasil analisis perhitungan regresi liner dan uji hipotesis, hasil perhitungan tersebut diolah dalam di bawah ini dalam bentuk hasil analisis regresi liner berganda pada masing-masing variabel dan hasil perhitungan uji t dan uji $f$. 
Tabel 5 Hasil Analisis Regresi Linier Berganda

\begin{tabular}{|c|c|c|c|c|c|}
\hline $\begin{array}{l}\text { Dependen } \\
\text { (Y) }\end{array}$ & $\begin{array}{c}\text { Independen } \\
(\mathrm{X})\end{array}$ & B & $\mathrm{t}$ & Sig & Pengaruh \\
\hline \multirow{6}{*}{$\begin{array}{l}\text { Keputusan } \\
\text { Memilih }\end{array}$} & Advertising & 0.176 & 2.200 & 0.029 & Positif dan signifikan \\
\hline & Sales Promotion & 0.024 & 0.306 & 0.760 & $\begin{array}{l}\text { Postitif dan tidak } \\
\text { signifikan }\end{array}$ \\
\hline & Personal Selling & -0.141 & -1.918 & 0.968 & $\begin{array}{l}\text { negatif dan tidak } \\
\text { signifikan }\end{array}$ \\
\hline & Public Relation & 0.581 & 6.893 & 0.000 & $\begin{array}{l}\text { Postitif dan } \\
\text { signifikan }\end{array}$ \\
\hline & Direct Marketing & 0.293 & 4.186 & 0.000 & $\begin{array}{l}\text { Postitif } \\
\text { signifikan }\end{array}$ \\
\hline & (Constant) & 0.249 & 1.989 & 0.048 & \\
\hline F hitung & 192.210 & & & & \\
\hline t tabel & 1.973 & & & & \\
\hline F tabel & 2,262149 & & & & \\
\hline $\mathrm{R}$ & 0,915 & & & & \\
\hline $\begin{array}{l}\text { Adjusted } \quad \mathrm{F} \\
\text { Scuare }\end{array}$ & 0,833 & & & & \\
\hline
\end{tabular}

Sumber: hasil penelitian, diolah tahun 2020

Pada pengujian secara parsial ini, dari lima variabel bauran promosi yang diuji terhadap keputusan memilih mahasiswa, diperolah ada 3 variabel bauran promosi yang berpengaruh signifikan yakni variabel advertising, variabel pulisitas dan varial direct marketing. Sementara dua variabel lainnya yakni variabel sales promotion dan personal selling tidak berpengaruh secara signifikan.

\section{Uji f}

Untuk mengetahui apakah variabel independent secara simultan (bersamasama) mempunyai pengaruh terhadap variabel dependent atau tidak berpengaruh maka digunakan uji F (F-test), dengan membandingkan $F_{\text {hitung dan }} \mathrm{F}_{\text {tabel }}$ pada taraf nyata $5 \% \quad(\alpha=0,05)$ atau perbandingan nilai signfikan F. Apabila Fhitung $>$ FTabel atau nilai Sig.F < 0,05 berarti $\mathrm{H}_{\mathrm{O}}$ ditolak, sebaliknya $\mathrm{F}_{\text {hitung }}<\mathrm{F}$ Tabel atau nilai Sig.F $>0,05$ berari $\mathrm{H}_{\mathrm{O}}$ diterima. Berdasarkan hasil analisis maka hasil uji F dapat disajikan pada Tabel berikut:

Tabel 6 Hasil Uji F (Simultan)

\begin{tabular}{|c|c|c|c|c|c|c|}
\hline \multicolumn{7}{|c|}{ ANOVA ${ }^{b}$} \\
\hline & odel & Sum of Squares & df & Mean Square & $\mathrm{F}$ & Sig. \\
\hline \multirow[t]{3}{*}{1} & Regression & 111.332 & 5 & 22.266 & 192.210 & $.000^{a}$ \\
\hline & Residual & 21.663 & 187 & .116 & & \\
\hline & Total & 132.995 & 192 & & & \\
\hline
\end{tabular}

Bauran promosi yang meliputi variabel advertising $\left(\mathrm{X}_{1}\right)$, sales promotion $\left(\mathrm{X}_{2}\right)$, personal selling $\left(\mathrm{X}_{3}\right)$, public relation $\left(\mathrm{X}_{4}\right)$ dan direct marketing $\left(\mathrm{X}_{5}\right)$ secara simultan berpengaruh signifikan terhadap pengambilan keputusan mahasiswa 
memilih Universitas Muhammadiyah Bengkulu. Uji F yang dilakukan dapat dilihat pada tabel berikut ini:

Tabel 7 Baurn Promosi Hasil Uji F/Simultan

\begin{tabular}{|c|c|c|}
\hline Hipotesis Alternatif $\left(\mathbf{H}_{\mathbf{a}}\right)$ & FTabel & Keterangan \\
\hline $\begin{array}{l}\text { Bauran promosi meliputi: } \\
\text { advertising }\left(\mathrm{X}_{1}\right), \\
\text { sales promotion }\left(\mathrm{X}_{2}\right), \\
\text { personal selling }\left(\mathrm{X}_{3}\right), \\
\text { public relation }\left(\mathrm{X}_{4}\right) \text { dan } \\
\text { direct marketing }\left(\mathrm{X}_{5}\right) \\
\text { secara simultan berpengaruh } \\
\text { signifikan terhadap } \\
\text { pengambilan keputusan } \\
\text { mahasiswa memilih } \mathrm{UMB}\end{array}$ & $\begin{array}{l}\mathrm{F}_{\text {hitung }}=192.210 \\
\mathrm{~F}_{\text {Tabel }}=2,262149 \\
\text { Sig. } \mathrm{F}=0,000\end{array}$ & $\begin{array}{l}\mathrm{H}_{\mathrm{a}} \text { diterima/ } \\
\mathrm{H}_{\mathrm{O}} \text { ditolak }\end{array}$ \\
\hline
\end{tabular}

Sumber: hasil penelitian, diolah tahun 2020

Berdasarkan hasil analisis regresi berganda dengan menggunakan $\mathrm{Df}_{1}=4$ dan $\mathrm{Df}_{2}=95$ pada alpha sebesar 5\% diperoleh $\mathrm{F}_{\text {Tabel }}$ sebesar 2,262149 sedangkan Fhitungnya diperoleh sebesar 192.210. Hasil pengujian menunjukkan nilai sig. $0.00<0.050$ dan nilai $\mathrm{F}_{\text {tabel }}=\mathrm{F}(\mathrm{k}, \mathrm{n}-\mathrm{k})=(5.188)=(0.05 ; 5,188)=2,262149$. Dengan demikian $\mathrm{F}_{\text {hitung }}$ lebih besar dari $\mathrm{F}$ tabel $\left(192.210>2\right.$,262149) maka $\mathrm{H}_{\mathrm{o}}$ ditolak dan $\mathrm{H}_{\mathrm{a}}$ diterima, sehingga hipotesis yang berbunyi bauran promosi meliputi advertising $\left(\mathrm{X}_{1}\right)$, sales promotion $\left(\mathrm{X}_{2}\right)$, personal selling $\left(\mathrm{X}_{3}\right)$, public relation $\left(\mathrm{X}_{4}\right)$ dan direct marketing $\left(\mathrm{X}_{5}\right)$ secara simultan berpengaruh signifikan terhadap pengambilan keputusan mahasiswa memilih Universitas Muhammadiyah Bengkulu diterima.

Selanjutnya hasil uji koefisien determinasi $\left(\mathrm{R}^{2}\right)$ yang pada intinya mengukur seberapa besar kemampuan model dalam menerangkan variasi variabel independent, Nilai koefisien determinasi $\left(\mathrm{R}^{2}\right)$ adalah nol dan satu. Nilai $\mathrm{R}^{2}$ yang rendah berarti kemampuan variabel-variabel independent dalam menjelaskan variasi variabel dependent amat terbatas atau kecil, sedangkan nilai yang mendekati satu berarti variabel-variabel independent memberikan hampir semua informasi yang dibutuhkan untuk memprediksi variabel independent.

Tabel 8 Hasil Uji Koefisien Determinasi

\begin{tabular}{lrrrr}
\hline \multicolumn{5}{c}{ Model Summary } \\
\hline Model & R & R Square & $\begin{array}{c}\text { Adjusted R } \\
\text { Square }\end{array}$ & \multicolumn{2}{c}{$\begin{array}{c}\text { Std. Error of the } \\
\text { Estimate }\end{array}$} \\
\hline 1 & $.915^{\mathrm{a}}$ & .837 & .833 & .34036 \\
\hline
\end{tabular}

Berdasarkan tabel 8 di atas dapat diketahui bahwa nilai-nilai koefisien determinasi tedapat pada Adjusted $\mathrm{R}$ Square sebesar 0,833. hal ini berarti kemapuan variabel bebas advertising $\left(\mathrm{X}_{1}\right)$, sales promotion $\left(\mathrm{X}_{2}\right)$, personal selling 
$\left(\mathrm{X}_{3}\right)$, public relation $\left(\mathrm{X}_{4}\right)$ dan direct marketing $\left(\mathrm{X}_{5}\right)$ dalam menjelaskan variabel terikat (keputusan memilih Univeristas Muhammadiyah Bengkulu) sebesar 83,3\% sedangkan sisanya $16,7 \%$ dijelaskan oleh variabel lain yang tidak dibahas dalam penelitian ini.

\section{PEMBAHASAN}

Bauran promosi dalam kegiatan promosi adalah suatu bentuk komunikasi pemasaran yang merupakan aktivitas pemasaran yang dilakukan oleh Universitas Muhammadiyah Bengkulu dalam upaya mencapai jumlah mahasiswa baru sesuai target setiap tahunnya. Untuk pencapaian target tersebut, Universitas Muhammadiyah Bengkulu harus mempau menjalankan roda organisasinya, hal ini disebabkan seluruh kegiatan yang ada di Universitas Muhammadiyah Bengkulu akan mampu dilaksanakan dengan biaya yang diperoleh dari mahasiswa yang melaksakan pendidikan perguruan tinggi pada Universitas Muhammadiyah Bengkulu.

Komunikasi pemasaran yaitu semua elemen-elemen promosi yang melibatkan komunikasi antar organisasi dan target (audience) pada segala bentuk yang ditujukan untuk memperolah performance pemasaran (Prisgunanto, 2006). Sejalan apa yang dinyatakan Prisgunanto tersebut maka diketahui bahwa kegiatan bauran promosi yang merupakan produk dari komunikasi pemasaran (Thadi, 2019) yang dilakukan Universitas Muhammadiyah Bengkulu merupakan hal yang penting, karena bauran promosi akan memberikan pengaruh positif apabila pelaksanaannya dilakukan secara benar dan tidak merubah nilai yang dianggap positif oleh masyarakat di Kota Bengkulu dan sekitarnya.

Universitas Muhammadiyah Bengkulu menjadikan bauran promosi sebagai kegiatan promosi sebagai salah satu komponen yang menjadi prioritas dari kegiatan pemasarannya, dengan adanya promosi maka calon mahasiswa baru akan mengetahui mengenai Universitas Muhammadiyah Bengkulu. Kotler \& Amstrong, (2012) menyatakan bahwa bauran pemasaran adalah seperangkat alat pemasaran taktis yang memadukan perusahaan untuk menghasilkan respon yang diinginkan dalam target pasar. Adapaun kegiatan promisi yang secara rutin dilakukan oleh Universitas Muhammadiyah Bengkulu untuk membagi informasi mengenai hal positif Universitas Muhammadiyah Bengkulu adalah menggunakan bauran promosi yakni advertising, sales promotion, personal selling publicitas dan direct marketing (Ningsih \& Hati, 2017).

Diketahui bahwa variabel pengaruh dalam penelitian adalah variabel bauran promosi di mana terdapat 5 (lima) variabel dalam kegiatan bauran promosi yakni advertising, sales promotion, personal selling, publicitas dan direct marketing, serta 1 (satu) variabel terpengaruh yakni keputusan memilih mahasiswa Universitas Muhammadiyah Bengkulu.

Berdasarkan hasil penelitian yang telah dilakukan oleh peneliti, maka diketahui bahwa seluruh kegiatan bauran promosi sebagai kegiatan promosi telah 
dilakukan sangat baik oleh Universitas Muhammadiyah Bengkulu berdasarkan jawaban responden yakni mahasiswa Universitas Muhammadiyah Bengkulu tahun masukan 2018/2019 sebagaimana sebaran pada analisis distribusi rata-rata atas jawaban 193 responden.

Keputusan memilih Universitas Muhammadiyah Bengkulu diketahui distribusi rata-rata skor jawaban sebesar 4, 29 dan kategori variabel berada pada interval 4,21-5,00 dan dalam kriteria sangat baik, adanya kecenderungan dalam diri mahasiswa maupun calon mahasiswa untuk memilih Universitas Muhammadiyah Bengkulu. Mahasiswa memiliki keputusan yang sangat baik dalam memutuskan memilih Universitas Muhammadiyah Bengkulu sebagai tempat melanjutkan pendidikan di perguruan tinggi, sehingga mahasiswa merasa bahwa melanjutkan studi di pendidikan tinggi di Universitas Muhammadiyah Bengkulu adalah hal yang sangat baik untuk dilakukan agar tujuan untuk mendapatkan pendidikan yang baik dan layak dapat terlaksana dengan optimal di Universitas Muhammadiyah Bengkulu.

Pada unsur pertama bauran promosi yakni advertising/periklanan, kegiatan iklan yang dilakukan oleh Universitas Muhammadiyah Bengkulu berpengaruh terhadap keputusan mahasiswa memilih Universitas Muhammadiyah Bengkulu, ini dikarenakan dengan menerima iklan yang bersifat informatif dari Universitas Muhammadiyah Bengkulu mengenai keunggulan Universitas Muhammadiyah Bengkulu maka calon mahasiswa dan mahasiswi akan mulai berpikir bahwa adanya keuntungan yang baik apabila mahasiswa memutuskan untuk melaksanakan pendidikan perguruan tinggi pada Universitas Muhammadiyah Bengkulu.

Mahasiswa menyadari bahwa kegiatan iklan pada Universitas Muhammadiyah Bengkulu telah dilakukan secara informatif, ini diketahui dari adanya penjelasan mengenai prosedur yang jelas, menampilkan seluruh produk Universitas Muhammadiyah Bengkulu, menampilan informasi yang sedetil mungkin tentang fakultas dan program studi yang paling diminati dan menginformasikan letak Universitas Muhammadiyah Bengkulu. Mahasiswa segala hal tersebut cukup melihat iklan yang ada, baik iklan lewat media televisi mampun lewat media cetak, sehingga mahasiswa mudah untuk mengakses dan mendalami informasi mengenai Universitas Muhammadiyah Bengkulu dengan baik. Baik secara parsial maupun secara simultan advertising berpengaruh signifikan terhadap keputusan memilih mahasiswa Universitas Muhammadiyah Bengkulu.

Pada unsur variabel sales promotion/promosi penjualan, tawaran beragam beasiswa membuat mahasiswa tertarik untuk mengetahui lebih lanjut mengenai produk (fakultas dan prodi) yang ada di UMB, dalam melakukan promosi Universitas Muhammadiyah Bengkulu sering melakukan kerjasama dengan sekolah-sekolah. Pemajangan spanduk dan alat promosi ditempat strategis dan di dalam lingkungan kantor. Walaupun secara parsial tidak berpeangaruh secara 
signifikan tetapi promisi penjualan secara simultan berpengaruh positif dalam keputusan mahasiswa memilih Universitas Muhammadiyah Bengkulu.

Pada unsur bauran promisi variabel personal selling atau penjualan pribadi (Zeithaml, 1988), Universitas Muhammadiyah Bengkulu memanfaatkan tenaga pendidikan dalam hal ini karyawan dan dosen membangun hubungan interaktif kepada mahasiswa dan calon mahasiswa sesuai waktu yang dibutuhkan, karyawan dan dosen mempresentasikan informasi secara aktif dan eduktif sehingga calon mahasiswa tahu apa yang dibutuhkan sebagai mahasiswa Universitas Muhammadiyah Bengkulu. Adanya pendekatan yang dilakukan oleh tenaga kependidikan saat memberikan informasi kepada mahasiswa, calon mahasiswa merasa bahwa informasi harus didengarkan dengan baik.

Penjualan personal merupakan salah satu alat promosi yang berpengaruh dalam kegiatan pemasaran, karena melalui personal selling pihah Universitas Muhammadiyah Bengkulu mampu memberikan informasi secara detail dan langsung kepada calon mahasiswa maupun mahasiswa mengenai kelebihan yang ditonjolkan oleh Universitas Muhammadiyah Bengkulu. Dengan demikian personal selling merupakan cara penjualan yang cukup efektif dalam mempengaruhi calon mahasiswa baru. Sebagaimana yang dikatakan oleh Buchari bahwa personal selling adalah penjualan pribadi yang melibatkan komunikasi interpersonal antara pembeli dan penjual untuk memenuhi kebutuhan pembeli untuk kepentingan kedua belah pihak (Buchari, 2011). Walaupun secara parsial tidak berpengaruh secara signifikan tetapi personal sellimg secara simultan berpengaruh positif dalam keputusan mahasiswa memilih Universitas Muhammadiyah Bengkulu.

Bauran promosi bidang publisitas, Universitas Muhammadiyah Bengkulu selalu mempublikasikan kegiatan kemahasiswaan di berbagai media, informasi yang disampaikan di media merupakan informasi positif yang dilakukan Universitas Muhammadiyah Bengkulu, Pihak Universitas Muhammadiyah Bengkulu selalu memasukan nilai produk pada setiap kesempatan sisi pembicaraan publik.

Publisitas merupakan suatu bentuk promosi non personal mengenai pelayanan atau kesatuan usaha tertentu dengan jalan mengulas informasi/berita tentang Universitas Muhammadiyah Bengkulu. Menurut Hermawan publisitas merupakan upaya komunikasi menyeluruh dari suatu perusahaan untuk mempengaruhi persepsi, opini, keyakinan dan sikap keberbagai kelompok terhadap perusahan tersebut (Hermawan, 2009). Yang dimaksud di sini adalah mereka yang terlibat, mempunyai kepentingan, dan dapat mempengaruhi kemampuan mencapai tujuan (Hidayat, 2018).

Seluruh eksistensi yang dimiliki Universitas Muhammadiyah Bengkulu harus dipublikasikan agar citra Universitas Muhammadiyah Bengkulu mampu kian meningkat, publisitas yang dilakukan Universitas Muhammadiyah Bengkulu adalah proses penyampaian informasi yang didesain untuk membangkitkan minat 
lebih tinggi pada masyarakat agar berpengaruh positif kepada mahasiswa untuk memilih Universitas Muhammadiyah Bengkulu. Baik secara parsial maupun simultan publikasi berpengaruh secara signifikan dalam keputusan mahasiswa memilih Universitas Muhammadiyah Bengkulu.

Petugas promosi UMB telah memberikan penjelasan tentang informasi produk secara menarik dan informatif, informasi Universitas Muhammadiyah Bengkulu dapat diperoleh lewat brosur atau katalog, dan ketersedian website membantu mahasiswa untuk mengetahui tentang produk (fakultas dan prodi) di Universitas Muhammadiyah Bengkulu. Website Universitas Muhammadiyah Bengkulu menyajikan informasi tentang produk secara rinci dan informatif. Dari pemasaran langsung menggunakan brosur, katalog dan website Universitas Muhammadiyah Bengkulu berpengaruh positif dan signfikan terhadap keputusan mahasiswa memilih Universitas Muhammadiyah Bengkulu dan ini sudah terujai berdasarkan hasil uji parsial dan simultan pada penelitian ini.

Hasil analisis advertising, publisitas/public relation dan direct marketing berpengaruh positif dan signifikan terhadap keputusan memilih Univeristas Muhammadiyah Bengkulu, sedangkan sales promotion dan personal selling secara parsial tidak segnifikan bepengaruh terhadap pengambilan keputusan mahasiswa memilih Universitas Muhammadiyah Bengkulu. Namun demikian bauran promosi yang meliputi advertising, sales promotion, personal selling, public relation dan direct marketing berpengaruh positif dan signifikan secara simultan terhadap pengambilan keputusan mahasiswa memilih Universitas Muhammadiyah Bengkulu.

\section{SIMPULAN}

Variabel advertising $\left(\mathrm{X}_{1}\right)$, public relation $\left(\mathrm{X}_{4}\right)$ dan direct marketing $\left(\mathrm{X}_{5}\right)$ secara parsial berpengaruh signifikan terhadap pengambilan keputusan mahasiswa memilih Universitas Muhammadiyah Bengkulu, pada sales promotion $\left(\mathrm{X}_{2}\right)$ dan personal selling $\left(\mathrm{X}_{3}\right)$ secara parsial tidak berpengaruh signifikan terhadap pengambilan keputusan mahasiswa. Bauran promosi meliputi advertising $\left(\mathrm{X}_{1}\right)$, sales promotion $\left(\mathrm{X}_{2}\right)$, personal selling $\left(\mathrm{X}_{3}\right)$, public relation $\left(\mathrm{X}_{4}\right)$ dan direct marketing $\left(\mathrm{X}_{5}\right)$ secara simultan berpengaruh signifikan terhadap pengambilan keputusan mahasiswa memilih Universitas Muhammadiyah Bengkulu

\section{DAFTAR PUSTAKA}

Buchari, A. (2011). Manajemen Pemasaran dan Pemasaran Jasa. Bandung: Alfabeta.

Hermawan, A. (2009). Penelitian Bisnis Paradigma Kuantitatif. Bandung: Grasindo.

Hidayat, D. P. (2018). Strategi Publisitas dalam Meningkatkan Brand Awareness RS Husada Utama Surabaya. Jurnal Spektrum Komunikasi, 6(2), 34-43. https://doi.org/10.37826/spektrum.v6i2.34 
Indasari, V. (2016). Pengaruh Kegiatan Promosi terhadap Preferensi Mahasiswa dalam Memilih Universitas Dahasen Bengkulu. Universitas Bengkulu: Tesis.

Johnson, D. P. (1994). Teori Sosiologi Klasik dan Modern. Gramedia Pustaka Utama.

Kotler, P., \& Amstrong. (2012). Prinsip-Prinsip Pemasaran (Edisi 13). Erlangga.

Lontoh, M. N. (2016). Analisis Pengaruh Bauran Promosi terhadap Keputusan Pembelian Mobil Toyota Pada PT. Hasjrat Abadi Manado Cabang Tendean. Jurnal Berkala Ilmiah Efisiensi, 16(01), 515-525.

Ningsih, Y. P., \& Hati, S. W. (2017). Pengaruh Bauran Promosi terhadap Keputusan Pembelian Produk Accu Yuasa Yang Dipromosikan Distributor PT Riau Indotama Abadi di Batam. Journal of Applied Business Administration, 1(1), 10-18. https://doi.org/10.30871/jaba.v1i1.1255

Prisgunanto, I. (2006). Komunikasi Pemasaran, Strategi dan Taktik. Jakarta:Ghalia Indonesia.

Schiffman, L., \& Kanuk, L. (2010). Consumer Behavior, 9th Edition. New Jersey: Pearson Prentice Hall.

Thadi, R. (2019). Proses Komunikasi Instruksional dalam Pembelajaran Vokasional. Journal of Education and Instruction (JOEAI), 2(1), 49-55. https://doi.org/10.31539/joeai.v2i1.614

Windusara, D. B. N., \& Kusuma, A. G. A. A. (2015). Pengaruh Bauran Promosi terhadap Keputusan Pembelian Oppo Smartphone. E-Jurnal Manajemen Universitas Udayana, 4(12), 4160-4185.

Zeithaml, V. A. (1988). Consumer Perceptions of Price, Quality, and Value: A Means-End Model and Synthesis of Evidence. Journal of Marketing, 52(3), 2-22. https://doi.org/10.1177/002224298805200302 